DOI:

\title{
НАЦИОНАЛЬНЫЕ ТРАДИЦИИ В СОВРЕМЕННОМ ДИЗАЙНЕ
}

\section{NATIONAL TRADITIONS IN MODERN DESIGN}

\author{
Екатерина Иванова \\ Российский государственный социальный университет \\ catherine.iva@mail.ru
}

\begin{abstract}
АННОТАЦИЯ
В статье дан краткий обзор истории дизайна, начиная с момента его формирования как отдельной сферы деятельности в конце XIX века и до наших дней, проведен анализ особенностей национальных школ дизайна, а также рассмотрены вопросы поиска баланса между универсальным и национальным в дизайне, изучен феномен этнической составляющей в поиске новых изобразительных форм в дизайне. Этно-культурный компонент имеет особое значение в развитии и поиске новых решений в дизайне, так как традиционные формы искусства адаптируются к принципам современного дизайна. Статью можно рассматривать как один из возможных методологических подходов к дальнейшим исследованиям, посвященным современному дизайну.
\end{abstract}

Ключевые слова: история дизайна; национальные школы дизайна; национальные традиции в дизайне; этнодизайн

Key words: history of design, national schools of design, national traditions in design, ethnodesign

Многофункциональная сфера дизайна вмещает широкий диапазон разнородных явлений. Дизайн, являясь сейчас одним из самых влиятельных видов проектно-художественной деятельности, объединяет элементы художественной и технической культуры. В период своего возникновения во второй половине XIX века дизайн во многом опирался на фундамент, заложенный декоративно-прикладным искусством. Изменение принципов производства, необходимость выпуска массовой 
продукции привели к универсализации принципов дизайна, оторвав его от истоков ремесленного производства, где применялся индивидуальный подход к созданию продукции. Несмотря на распространение сферы универсального и интернационального, черты национального присутствуют в мире вещей так же, как и черты общности.

Методология исследования обусловлена спецификой описываемого явления. Были использованы следующие научные подходы: социальнокультурный подход к исследованию, позволивший выявить объективные закономерности изменений в восприятии художественных концепций в связи с социальными и культурными изменениями в обществе. Искусствоведческий подход способствовал объективному пониманию дизайна как компонента современной художественной культуры. Семиотический подход способствовал анализу символических элементов дизайна, которые накапливают и передают информацию с помощью символов и знаков, отраженных в художественном решении формы, цвета, декоративном решении и т. д.

Говоря о национальной составляющей в дизайне, мы должны обратиться к истории дизайна и рассмотреть вопросы закономерных изменений в восприятии художественных явлений в сфере дизайна. Дизайн как самостоятельная область деятельности начинает формироваться во второй половине XIX века под влиянием социокультурных и экономических изменений в обществе. Английское художественное движение искусств и ремесел, возникшее в конце XIX века, послужило одной из отправных точек для формирования современного дизайна. Участники движения стремились к сближению искусства и ремесла, идеализируя самобытное творчество ремесленников средневековья.

В период промышленной революции в обиходе европейцев появляются обезличенные, однотипные предметы. Такая ситуация вызывает протест у представителей движения искусств и ремесел. Уильям Моррис (William Morris, 1834-1896) и другие прерафаэлиты, идеализируя средневековье, разделяли веру английского искусствоведа и социального реформатора Джона Раскина (John Ruskin, 1819-1900) в превосходство товаров ручного изготовления перед изделиями фабричного производства. Раскин, отвергая машинное производство, выдвигал идею соответствия мира вещей миру людей. Моррис сформулировал принцип целесообразности формы, вывел принципы соотнесения формы, где украшение и отделка предмета соответствуют его назначению. Моррис стоял у истоков концепции эстетического синтеза, где все элементы среды обитания связаны в единое целое. Надо отметить, что в России идеи Раскина и Морриса проявились в сходных проектах, таких как Абрамцево и Талашкино. В период конца XIX века остро встают и вопросы поиска национального стиля в искусстве. 
Рождение нового стиля виделось Джону Раскину в середине XIX века как рождение нового языка. Архитектор, изучая наследие прошлого, прежде всего готической эпохи, как наполненной наибольшим символическим содержанием, отражающим в орнаменте божественный порядок, должен адаптировать его к настоящему, демонстрирующему упадок в области дизайна.

Надо отметить, во Франции второй половины XIX века вопросы поиска национального стиля, теории и практики орнамента в дизайне были не менее актуальны, чем в Англии. В связи с этим следует выделить имя архитектора, реставратора, искусствоведа, историка архитектуры и идеолога неоготики Эжена Эмануэля Виолле-ле-Дюка (Eugène Emmanuel Viollet-le-Duc, 1814-1879). Будучи основоположником архитектурной реставрации, он ценил готический орнамент, прежде всего, за его технологическую составляющую. В то время как Рёскин превозносил иррациональность готики и изучал правдивый характер отражения природы в орнаменте, Виолле-ле-Дюк отмечал рациональность готических строений, функциональность конструктивных элементов (Иванов 2010: 96).

В дизайне Германии, пожалуй, раньше, чем в других странах Европы, закладываются тенденции функционализма. Уважительное отношение к структуре вещей, техническим аспектам дизайна заложил еще Готфрид Земпер (Gottfried Semper, 1803-1879), хотя творчество его приходится на период эклектики. Стиль, центральное понятие теории Земпера, формируется, изменяясь под действием ряда обстоятельств: традиции, религиозной обрядовости, месторасположения, климата, использования материала и технических достижений. В определении стиля Земпер придерживается превалирующего тогда понимания стиля как всеобъемлющего порядка. Земпер видел причины упадка архитектуры и художественных ремесел в отрыве украшения от конструкции. Не являясь активным противником развития производства, он пытался выявить новую эстетику предмета, созданного машинным способом. В своих исследованиях материальной культуры Земпер заложил ключевые принципы формообразования в промышленности и основы технической эстетики (Хомякова 2012: 19).

Зафиксировав после первой всемирной выставки 1851 г. разрыв между назначением представленных на выставке вещей и их дизайном, Земпер призвал изменить принципы обучения дизайнеров, обратившись к изучению художественного наследия прошлого.

Для английского теоретика, архитектора и дизайнера Огастеса Уэлби Нормора Пьюджина (Augustus Welby Northmore Pugin, 1812-1852) также была важна функциональность конструктивных элементов, как и для Виолле-ле-Дюка, и он формулирует принципы „соответствия 
декора", которыми стали широко пользоваться при подготовке дизайнеров в школе дизайна в Лондоне.

Алоиз Ригль (Alois Riegl, 1858-1905) - австрийский теоретик и историк искусства, профессор Венского университета, представитель венской школы искусствознания. Наряду с Генрихом Вёльфлином (Heinrich Wölfflin) он стал одним из двух влиятельных искусствоведов начала XX века. Однако, в сравнении с основными понятиями Вёльфлина, идеи Ригля намечают гораздо более динамичную панораму историко-художественного процесса, где главной движущей силой является обоснованный им принцип художественной воли как источника творчества. Именно художественная воля, по мнению Ригля предопределяла своеобразие эпох искусства. Он разработал теорию гаптической (осязательно-плоскостной) и оптической (пространственной) трактовки формы. Основополагающая книга Ригля „Проблемы стиля. Основы истории орнамента” написана в 1893 г. Основным принципом для Ригля является „воля к форме” или художественная воля, которую следует понимать не как субъективноиндивидуалистическое волеизъявление, но как некое сверхличное воление (Wollen), реализующееся, если говорить о художественной эпохе в целом, в смене стилистического курса. Ригль подвергает коренному пересмотру традиционно сложившиеся иерархии видов искусства, равно как и исторических эпох. Декоративные виды творчества, прежде считавшиеся второстепенными, как выясняется, гораздо нагляднее демонстрируют доминирующую формотворческую волю; равно и эпохи, прежде считавшиеся „упадочными”, предстают временем поразительных стилистических новаций, что детально продемонстрировано в выдающемся труде Ригля „Позднеримская художественная промышленность” (1901), где мнимый „упадок” искусства Древнего Рима трактован как великая, провиденческая смена эстетических вех: гаптическое, чувственно-осязательное восприятие сменяется в позднеримский период оптическим, ориентирующимся на зрительные, более интеллектуализованные ценности. Эта линия наглядно прослеживается в статье „Настроение как предмет новоевропейского искусства” (1899) и большой работе „Голландский групповой портрет” (1902). С годами концепции Ригля обретают все более масштабный, общекультурологический характер, свойственный, например, его лекциям, собранным в посмертно изданной книге „Складывание искусства барокко в Риме” (1908). Интерес к широким этнографическим, обобщениям, проявившийся уже в „Проблемах стиля”, где он различает народы Запада, более склонные к новаторству, и народы Востока, якобы более консервативные, тут проступает еще четче. История искусств предстает 
полем взаимодействия не только неких стилистических принципов, но народов, данные принципы в своей судьбе воплощающих. Идея художественной воли А. Ригля оказала сильнейшее влияние на искусство модерна (Иванов 2010).

Развитие стиля модерн пошло по пути разделения формообразования на конструктивное и декоративное начало. Конструкция из утилитарного явления становится эстетически значимой, а декоративность представляется как соединение изобразительного и абстрактного начала. Тема построения единого стиля всего человеческого окружения, от архитектуры до деталей предметов обихода, культивировала чувство цельности, что способствовало формированию характерного для будущего дизайна мышления как чего-то целого с неразделенностью функционального и эстетического. Модерн, отказавшись от иерархии видов и жанров искусства, открывал путь к тому, чтобы увидеть в бытовом проектировании полноценное художественное творчество (Хомякова 2012: 20).

Поиск русского национального стиля был аналогичен по своему содержанию процессам, происходящим в предметной культуре, изобразительном искусстве, архитектуре других стран Европы и особенно Англии. Как У. Моррис находит идеалы средневекового искусства, возрождая ремесла, так и деятели Абрамцевских мастерских обратили свой взор в сторону византийского орнамента первых книгопечатных изданий и образцов архитектуры Владимиро-суздальской Руси (Хомкова 2012: 71). Однако Григорий Юрьевич Стернин пишет: „обращаясь к своей собственной старине, пытаясь подчеркнуть в искусстве особый национальный колорит, русские художники, таким образом, лишь выражали общую тенденцию, существовавшую внутри европейского „нового стиля”” (Стернин 1970: 195).

Архитектор, лидер Чикагской школы Луис Салливан (Louis Henry Sullivan) еще в 1900 г. провозгласил знаменитый принцип „форма определяется функцией”, тем самым пытаясь перенести в сферу человеческой деятельности закономерности живой природы, где существует огромное многообразие форм, удивительно пригнанных к функциональным особенностям биологических объектов. Эта формула охватывает всю сложную совокупность материально-духовных функций предметного наполнения среды окружающего человека. Архитектор Адольф Лоос (Adolf Loos) развил идеи Салливана, считая архитектуру только функциональным проектированием, его девиз „Форма зависит от утилитарной функции" был направлен против орнаментализма, фасадничества и внешней декорации.

Один из величайших американских архитекторов Фрэнк Ллойд Райт (Frank Lloyd Wright) раздвинул границы формулы Салливена и 
Лооса - „форма и функция едины”. Особенно активно он пропагандировал идеи комплексных проектов, корректных по отношению к окружающей среде. Именно ему принадлежит развитие в дальнейшем особого направления - органической архитектуры. Он же расширил понимание функции, заявив, что они могут быть не только утилитарными, но и информационными, культурными, знаковыми, символическими, технологическими, даже познавательными (Хомякова 2012:24).

В процесс становления дизайна огромный вклад внесла школа Баухауз (Bauhaus, 1919-1933). История Баухауза - это история взглядов и деятельности его руководителей: сначала Вальтера Гропиуса (Walter Adolph Georg Gropius), потом Адольфа Мейера (Adolf Meyer), затем Мис ван дер Роэ (Ludwig Mies van der Rohe). Школа Баухауз за кототкий срок своего существования совершила переход от традиционного ремесла, с увлечением народными мотивами и стилистикой модерна к художественному проектированию. Деятельность Баухауз оказалась рубежным периодом в практике предметного искусства. Если до Баухауз декоративно-прикладное искусство находилось в активной противопоставленности машинному производству, то после опытов Баухауз, оно было приспособлено к потребностям нового времени. Принцип целесообразности вышел на уровень эстетического понимания. Именно внутри Баухауз произошло рождение классической формулы функционализма как основного формообразующего принципа дизайна XX в. (Хомякова 2012: 21).

Важную роль в процессе рождения и становления российского дизайна сыграл ВХУТЕМАС (Высшие художественно-технические мастерские). Во ВХУТЕМАС разрабатывали следующие вопросы: проблемы комплексного проектирования; поиски многофункциональности вещи, актуализация эстетических свойств материала, решение вопросов стандартизации и пр. ВХУТЕМАС стал центром поисков новых формообразующих подходов и внес устойчивый вклад в развитие российской проектной культуры и дизайна. В 1927 г. ВХУТЕМАС был переименован во ВХУТЕИН - Высший художественно-технический институт (Ковешникова 2011). Приемником художественных принципов российской школы дизайна в настоящее время является Московская государственная художественно-промышленная академия им.С. Г. Строганова.

Общей стратегией развития мирового дизайна 1950-1970 гг. стал функционализм, проявление которого можно обнаружить во всех объектах проектной культуры. Функциональный дизайн, по словам Александра Николаевича Лаврентьева стал своего рода „интернациональным дизайн-стилем" (Лаврентьев 2008: 199). Немецкая 
школа формообразования Ульме (1949-1965 гг.) характеризуется утрированной рационализацией, абсолютизацией научных методов в проектировании, отказом от доминирования творческой индивидуальности.

Начиная с периода функционализма, одной из тенденций дизайна является стремление распространить некую унифицированную форму вне культурно-регионального контекста. Как отмечает Николай Александрович Иванов, „навязчивой идеей модернизма являлась мысль о прозрачности, некой предельности выражения визуального порядка дизайна. Отсутствие „лишних” деталей, в которые в первую очередь попал орнамент, свидетельствовало в модернизме о четкости, „искренности”, направленности на объяснение и представление главного, которое выводится в объекте дизайна на первый план, а второй план, в который некогда входило связанное с украшением, становится излишеством" (Иванов 2010:127).

В противоположность модернизму, постмодернистская парадигма позволяет эклектическое цитирование существовавших в прошлом визуальных элементов архитектуры объектов творчества дизайнера, этнографических поделок, предметов археологических раскопок и т.п. становится возможным в современном дизайне, служит характерным маркером принадлежности работ к постмодернизму (Иванов 2010: 133). Постмодернизм приветствует разнообразие, он предпочитает смеси чистым формам и поощряет одновременно существующее множество разных прочтений одного и того же объекта с целью усилить производимый им экспрессивный эффект (Иванов 2010: 134). Стратегия постмодерна в своем наиболее чистом виде обнаруживает выражение в многообразии культурных и исторических рефлексий, в том числе и орнаментальных (Иванов 2010: 135). Активно используется народный орнамент в творчестве современных европейских дизайнеров Каффе Фассетта (Kaffe Fassett), Кима Маклина (Kim McLean), Филипа Якобса (Philip Jacobs), Кейко Гаука (Keiko Gauk), где не узнаваемы источники происхождения орнаментальных композиций, а образцы, выполненные на ткани, мозаике, керамике, тяготеют к яркости, многоцветности, сохраняют мотивы, свойственные народной культуре вообще и отдельно напоминают праздничную крестьянскую орнаментику (Иванов 2010:136).

В современном дизайне можно выявить две тенденции: первая развивает идеи функционализма и унификации в сфере дизайн-проектирования, вторая тенденция противоположна ей, и напротив стремится подчеркнуть и выявить региональный, национальный, этнический аспект при создании дизайн-объектов. Следует отметить, что в сфере дизайна появляются объекты, источником творчества которых выступали 
образы и формы народного искусства. Часто такого рода реминисценции обозначают термином этнодизайн. Теоретическая основа понятия этнодизайн еще не до конца сформирована, что рождает дискуссионность этого явления, так часто его упрекают в склонности к излишнему украшательству. Тем не менее, использование этнических мотивов, в том числе орнаментальных становится одной из характерных тенденций современного дизайна. Так появляется понятие этнического стиля: японский стиль, африканский стиль, кельтский стиль и т. д.

Механизм отбора импульсов этнического искусства, воспринимаемых дизайном, действует в широком диапазоне: цитирование, основанное на воспроизведении оригинальной композиции традиционного искусства; стилизованные объекты на тему традиционного искусства; объекты, основанные на авторском интуитивном решении, содержащие ассоциативную трактовку традиций и материала визуального искусства.

В качестве примера, отражающего этническую составляющую в дизайне среды приведем дизайн-проект этно-культурного центра при представительстве республики Коми в Москве. Проект разработан студентами кафедры искусств и художественного творчества Российского государственного социального университета - Мусаевой Кариной и Тырбылевой Анастасией под руководством Ивановой Екатерины Ю. (доцент, кандидат культурологии) и Лаврентьевой Оксаны С. (доцент, кандидат педагогических наук). За основу проекта была взята тема традиционного жилища коми - изба. Поэтому проект предусматривает большое количество предметов из дерева, включенных в интерьер. Большое внимание уделено декоративным элементам, которые представлены как в виде традиционных орнаментов, так и иллюстративных композиций на тему народного эпоса коми и традиционных предметов быта. Таким образом, современный интерьер обогащается элементами традиционной культуры, которые не только не диссонируют с ним, но напротив, создают теплую атмосферу, располагающую к изучению культурных традиций народа коми.

Отражение этнокультурных традиций в дизайне находит свое выражение как в прямом цитировании объектов этнического искусства, так и в трансформации визуального материала, которая рождает новые формы, однако сохраняющие визуальную связь с прототипом - аллюзия, парафраза.

Знание архетипических образцов, пусть и трансформированных в творческой работе дизайнера, необходимо в проектной деятельности. Выбор знаковой основы, знание семантики очень важно в современном дизайне. Дизайн способствует интеграции традиционных этнических символов в современную культуру, таким образом культура 
сохраняется не только в музейных и реконструированных формах. Интегрирующая роль дизайна способствует приемственности и сохранению национальных традиций.

Таким образом, помимо тенденции преобладания интернациональных качеств в современном дизайне, можно отметить и стремление к ассоциированию его с самобытным культурным наследием. Надо отменить, что в некоторых странах культурная традиция и дизайн тесно взаимосвязаны, например, в Японии, Швеции, Италии. Интересно в этом контексте отметить и Ирландию, для которой кельтский орнамент стал своего рода визитной карточкой, символом национальной идентичности.

Конечно, в настоящее время культурные обмены между народами стали значительно интенсивнее, и элементы одних культур, активно проникают в другие, и в этой ситуации тем более значимо умение дизайнера узнать, вычленить, правильно трактовать элементы этнической визуальной культуры. Приведем в пример еще один проект разработанный студенткой кафедры искусств и художественного творчества Российского государственного социального университета - Кравченко Варварой, которая разработала графические элементы фирменного стиля греческого кафе „Калимера” в Москве. В данном случае проект базировался на ассоциативном ряде изобразительных элементов. Все элементы стилизованы и шаржированы, но носят узнаваемый характер, апеллируя к древнегреческой мифологии.

Художественная формула этнического искусства, основанная на традиционных формах, содержит в себе фундаментальные архетипы традиционной культуры. Включая в свою практику такие понятия как архетип, символ, знак, метафора, ассоциация и т.п., дизайн стремится к возрождению семиотических ценностей формы.

Отношение к этнической составляющей в дизайне меняется от увлеченности визуальными этническими компонентами до полного их отрицания в зависимости от мировоззренческих установок господствующих в обществе и в частности художественной среде. И видимо лишь поиск гармоничного баланса интернационального и национального способен решить эту проблему.

В заключении хочется отметить, что данное исследование является источником информации для изучения и применения в современной дизайнерской практике элементов этнической культуры. Адаптируя многовековые народные и национальные традиции прикладного искусства, можно сформировать уникальный симбиоз современного дизайна и образцов искусства традиционных культур, который может послужить источником вдохновения для реализации художественных задач в проектной деятельности современного дизайнера. 
Историческое и культурное наследие каждого народа содержит художественные идеи, которые передаются из поколения в поколение, являясь благотворной почвой для формирования культурной среды и национальных традиций. Таким образом, помимо распространения международных универсальных принципов в области дизайна, можно отметить его связь с самобытными явлениями культуры. Одним из важных аспектов в сфере изучения национальных составляющих в дизайне является изучение возможностей использования этнического орнамента в современном дизайне. Основной особенностью включения этнического, национального компонента в дизайн является осознание своей культурной идентичности, что не противоречит необходимости быть включеными в общее культурное развитие. Одним из приоритетных направлений в развитии современного дизайна становится стремление подчеркнуть национальную идентичность. В настоящее время во многих школах дизайна большое внимание уделяется изучению истории, природных условий, духовного опыта и традиций материальной культуры различных народов, включения их традиций в динамику развития современного искусства. Каждому народу, независимо от того, на какой стадии культурного развития он находится, присуще желание создавать красивые формы. Подобно тому, как художники, архитекторы и дизайнеры в поисках нового стиля в конце XIX - начале $\mathrm{XX}$ вв. вглядывались в средневековое прошлое своих стран, находя в средневековье свою национальную идентичность, так и теперь, хотя это может показаться парадоксальным, взгляд в прошлое, часто связан с поиском новых форм искусства, переосмыслением художественных традиций прошлого.

В результате исследования можно сделать следующие выводы:

1. Необходимо изучать этническое искусство и возможности включения его форм и художественных образов в сферу деятельности дизайна. Новая сфера применения традиционных форм культуры и искусства должна стать одним из важнейших направлений в работе дизайнера, что позволит сохранить этнокультурный компонент в современном дизайне.

2. Цвет, ритм, фактура и текстура - средства композиции, которые применимы как для дизайна, так и для декоративно-прикладного искусства, поэтому композиционные приёмы могли бы быть объединяющим средством традиционных искусств и дизайна.

3. Исследования в области современного этнодизайна помогли бы сформировать наиболее полную картину взаимодействия национального прикладного искусства и дизайна. 


\section{SUMMARY}

The article focuses on the history of design starting with its formation as a discipline in the end of the 19th century and up to nowadays. The analysis of the peculiarities of national design schools is introduced. The issues of balance between the universal and the national in design are considered paying attention to the phenomenon of the ethnical component in searching for new visual forms in design. The ethnocultural component plays a significant role in the development of new solutions for design, as the traditional forms of art are adjustable to the principles of modern design. The study introduces one of the methodological approaches to further research in modern design.

\section{ЛИТЕРАТУРА}

Иванов 2010

Ковешникова 2011

Лаврентьев 2008

Хомякова 2012

Стернин 1970
Иванов, Н. А. (2010) Орнамент в западноевропейской теории дизайна XIX-XXI вв. Диссертация кандидата искусствоведения. Санкт-Петербург.

Ковешникова, Н. А. (2011) История дизайна. Москва: Омега-Л.

Лаврентьев, А. Н. (2008) История дизайна. Москва: Гвардарики.

Хомякова, И. В. (2012) Взаимодействие экокультурных практик регионального дизайна и народного искусства: на материале Республики Мордовия. Диссертация .. кандидата искусствоведения. Саранск.

Стернин, Г. Ю. (1970) Художественная жизнь России на рубеже XIX-XX веков. Москва: Искусство. 